\title{
SEA ICE PREDiction: The Development OF A SUITE OF SEA-ICE ForECASTING SYSTEMS FOR THE NORTHERN HEMISPHERE
}

\author{
By Ruth H. Preller
}

. . accurate

forecasts of the

variability of sea-ice

conditions . . . can

provide valuable

information to both

naval and commercial

operations.
$T$ HE LAYER of ice and snow that covers the Arctic Ocean and its marginal seas is highly variable in nature. Satellite imagery of the ice cover (Parkinson, 1991) has shown great interannual variability in the monthly averaged sea-ice distribution over the past 15 years. Although the central Arctic has its greatest variability in the summer, many of the marginal seas, which are ice covered in winter only (e.g., Bering Sea and the Sea of Okhotsk), exhibit the greatest variability in winter. The seasonal cycle of ice growth and decay has also been observed to vary from region to region and from year to year (Parkinson et al., 1987). On average. the ice cover in the northern hemisphere reaches its maximum extent in March and its minimum extent in September.

The variability in the extent of the ice cover is due to a number of different forces acting on the ice. Heating and cooling from both the atmosphere and the ocean are responsible for the growth and decay of sea ice. In addition. the ice cover, with the exception of shorefast ice, (ice attached to the shore) is in a state of nearly constant motion and deformation. Deformation of the ice causes the formation of ridges, leads, ice rubble, and ice floes.

The variability exhibited by the polar oceans exerts a strong influence on global climatology. In winter, the ice cover acts as an insulator limiting the heat exchange between the cold atmosphere and the relatively warm ocean. In summer, the ice cover reduces the total solar heating of the earth's surface by reflecting four to seven times the amount of solar radiation reflected by open water (Parkinson et al., 1987). Feedbacks among surface albedo, ice extent, snow cover, and the global heat budget are crucial in the determination of global climatology.

On shorter time scales, accurate forecasts of the variability of sea-ice conditions in the polar

R.H. Preller, Naval Research Laboratory. Stennis Space Center, MS 39529, USA. oceans can provide valuable information to both naval and commercial operations. Ships and field operations benefit by knowing the thickness of the ice, the movement of the ice (ice drift), and the location of the ice cover (versus open water).

The Navy/National Oceanic and Atmospheric Administration (NOAA) Joint Ice Center (JIC) located in Suitland, MD, is actively engaged in global sea-ice analysis and forecasting. Most of the JIC's users are either commercial or Navy fleet operators who require ice-edge information during the course of operations. In response to the need of these users, the JIC creates both a 7-day forecast of ice-edge location and a weekly ice-concentration (percentage of ocean area covered by sea ice) analysis. The ice-concentration analysis is derived mainly from satellite data. In addition. numerical models are providing products. such as forecasts of ice drift, that are used as guidance by the JIC in determining the 7-day forecast of change in the ice-edge location.

\section{Numerical Models of Sea Ice}

Our understanding of the dynamics and thermodynamics of sea ice has increased substantially over the past 20 years. Observational data from field experiments, such as the Arctic Ice Dynamics Joint Experiment (AIDJEX) and the Marginal Ice Zone Experiment (MIZEX), and remotely sensed data have provided enough information to design some very sophisticated models of the behavior of sea ice. Various types of ice models-dynamic, thermodynamic, and dynamic-thermodynamichave been developed and applied to both the Arctic and Antarctic.

The simplest dynamic ice model, used to determine ice motion, is based on a balance of forces between wind and water stresses and the Coriolis force. This "free drift" model is often a good approximation away from boundaries and under divergent conditions. However, ice drift may be adjusted significantly in both magnitude and direction by internal ice stress. Near coastlines and in regions where convergence is taking place, stress 
on the ice can cause ridging and ice deformation to occur. Models that include internal ice stress contain a constitutive law that treats ice as a viscous, elastic, viscous-plastic, or elastic-plastic medium. Most ice models make the assumption that ice acts as a continuum, a continuous medium, not as a field of individual floes. Although this assumption may be valid in the central Arctic, it is not very useful in the marginal ice zone (e.g., the Greenland Sea). Research to develop more accurate, realistic ice rheologies is an ongoing effort.

Thermodynamic ice models address the evolution of the mean ice/snow thickness based on the combined effects of atmospheric heat fluxes and oceanic heat fluxes. These heat fluxes are transported in the snow/ice layer by conduction. The surface heat balance consists of shortwave radiation, modified by the effects of albedo, incoming and outgoing longwave radiation, sensible heat flux, and latent heat flux. The oceanic heat flux is the amount of heat added or removed from the ocean's mixed-layer, which lies directly beneath the ice cover. Heat is added or removed from this layer by horizontal advection or by heating from beneath the layer.

Dynamic-thermodynamic models integrate the important effects of ice motion and ice growth/ decay into one model. Most of these ice models use constant or prescribed ocean currents and heat fluxes. However, to accurately predict the variability of the ice-edge location, it is necessary to provide the appropriate variability in the ocean forcing. This has been done by coupling dynamicthermodynamic ocean models to the ice models.

\section{U.S. Navy Sea Ice Forecasting Systems}

Over the past 7 years, the Naval Research Laboratory (NRL) has undertaken the design of operational sea-ice forecasting systems capable of providing guidance products to the JIC for the Arctic and its subregions. At the center of these forecast systems is a numerical sea-ice model.

Three such forecast systems are run operationally at the Fleet Numerical Oceanography Center (FNOC) located in Monterey, CA. The first system to be developed, the Polar Ice Prediction System (PIPS), encompasses the central Arctic basin, the Barents, and the Greenland Seas (Fig. 1). The two more recent systems are higher-resolution regional versions that encompass a particular basin. The Regional Polar Ice Prediction System-Barents Sea (RPIPS-B) covers the Barents Sea and the western part of the Kara Sea, as well as the White Sea. The Regional Polar Ice Prediction SystemGreenland Sea (RPIPS-G) covers the region adjacent to the east Greenland coast. PIPS uses a grid resolution of $127 \mathrm{~km}$, RPIPS-B uses $25 \mathrm{~km}$, and RPIPS-G uses $20 \mathrm{~km}$.

Each of these forecast systems has the same basic design (Fig. 2) centered around a dynamicthermodynamic sea-ice model (Hibler 1979 and

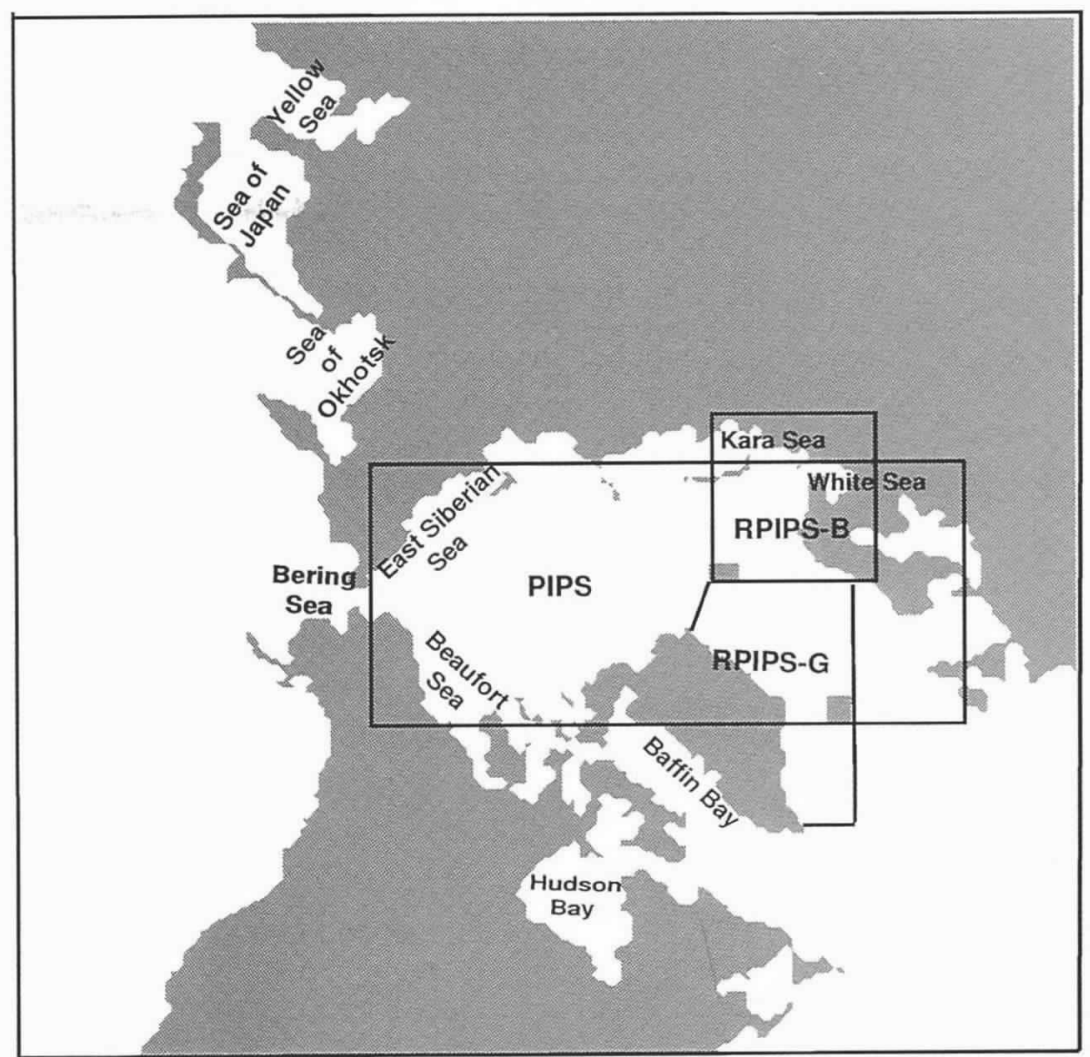

Fig. 1: The region covered by the Polar Ice Prediction System (PIPS) 2.0 forecast system with the boundaries of the PIPS, the Regional Polar Ice Prediction System-Barents Sea (RPIPS-B), and the Regional Polar Ice Prediction System-Greenland Sea (RPIPS-G) domains included.

1980). The model has the ability to determine ice drift, thickness, and concentration (including the location of the ice edge). It consists of five major components: 1) momentum balance, which includes wind and water stresses, the Coriolis force,

\section{POLAR ICE PREDICTION SYSTEM (PIPS)}

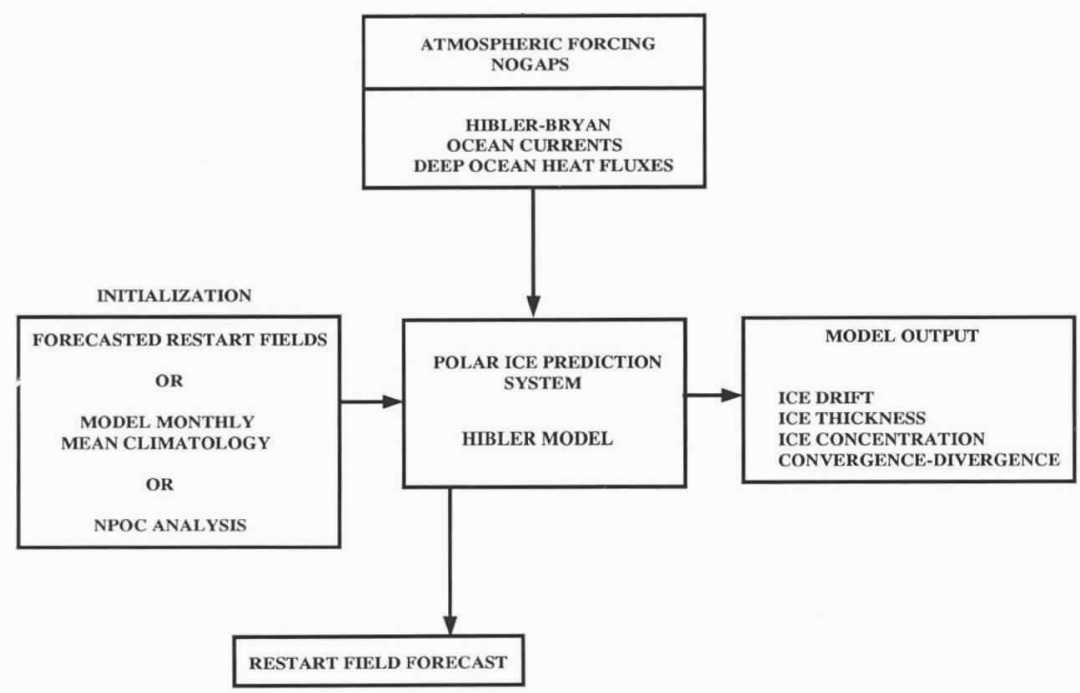

Fig. 2: A schematic of the design of the PIPS and RPIPS forecast systems. 
and inertial forces; 2) ice rheology, relating ice stress to ice deformation; 3) ice-thickness distribution; 4) ice-strength formulation; and 5) atmosphere-ice-ocean heat budget. The Navy's atmospheric forecast model, the Navy Operational Global Atmospheric Prediction System (NOGAPS) (Hogan et al., 1991) provides the necessary atmospheric forcing (i.e., the winds, surface air
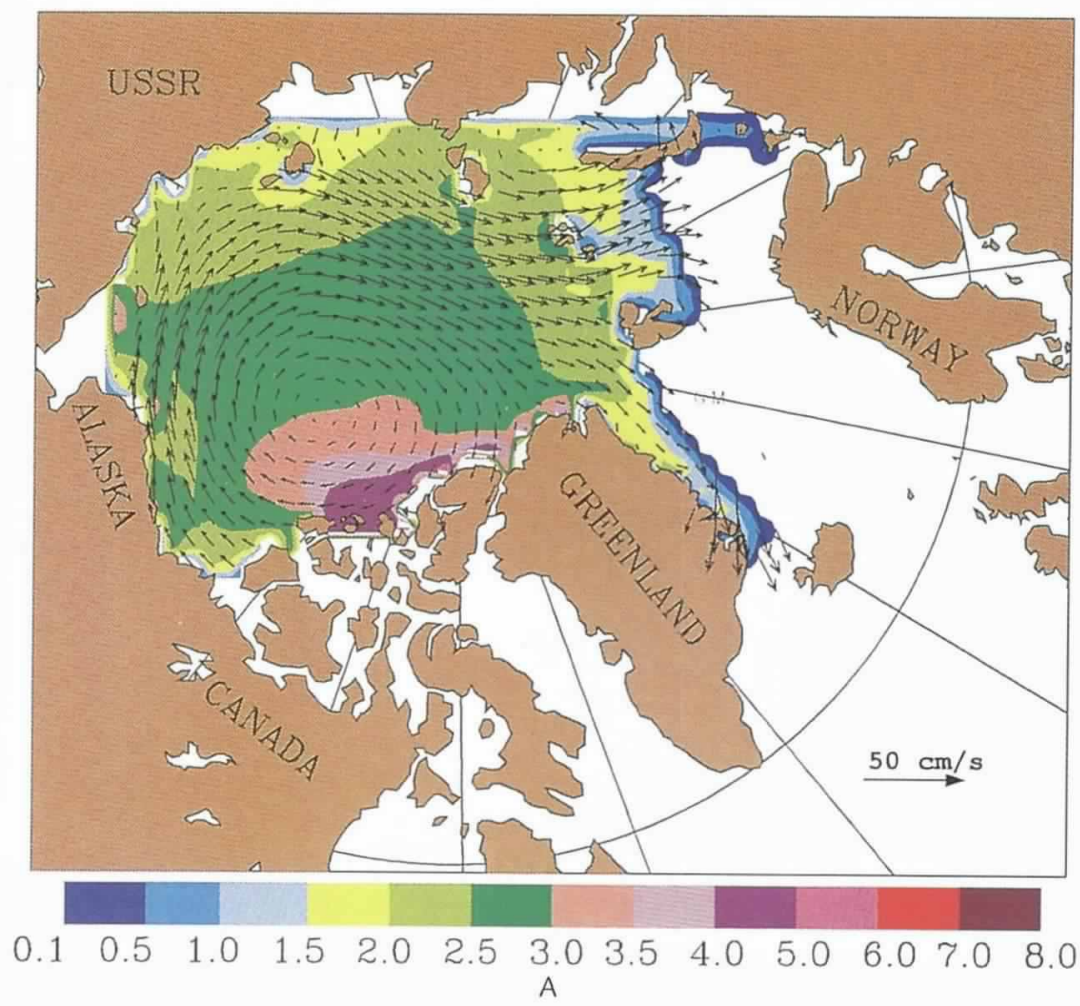

temperatures, and atmospheric heat fluxes) needed to drive the ice model. Oceanic forcing is specified in the form of monthly mean ocean currents and heat fluxes derived from a coupled iceocean model (Hibler and Bryan, 1987). The forecast systems are used to make a 120-hour forecast each day. The ice model is initialized daily from the previous day's 24 -hour forecast. The regional models also require ice-thickness information from PIPS to serve as ice-inflow boundary conditions at the open boundaries (Preller et al., 1989). If for any reason the 24-hour forecast is not available, each model is initialized from a model-derived monthly mean climatology.

Once each week, the model's ice concentration is initialized from observations. The ice-thickness fields and ocean temperatures are adjusted at the ice edge to agree with the observations (Preller and Posey, 1989), which are a digitized form of the JIC ice-concentration analysis. This analysis is derived from a number of different sources of satellite data: infrared imagery comes from the Advanced Very High Resolution Radiometer (AVHRR) on board the NOAA polar-orbiting satellite; visible-band imagery is obtained from the Defense Meteorological Satellite Program's (DMSP) Optical Line Scanner (OLS) operated by the U.S. Air Force; and passive microwave data (brightness temperatures) comes from the Special Sensor Microwave Imager (SSMI) carried on board the DMSP "morning" satellite. In addition to this, available data from ice reconnaissance flights or ship observations are included (Wohl, 1991). Recently, SSMI ice-concentration data have become available in real time at FNOC.

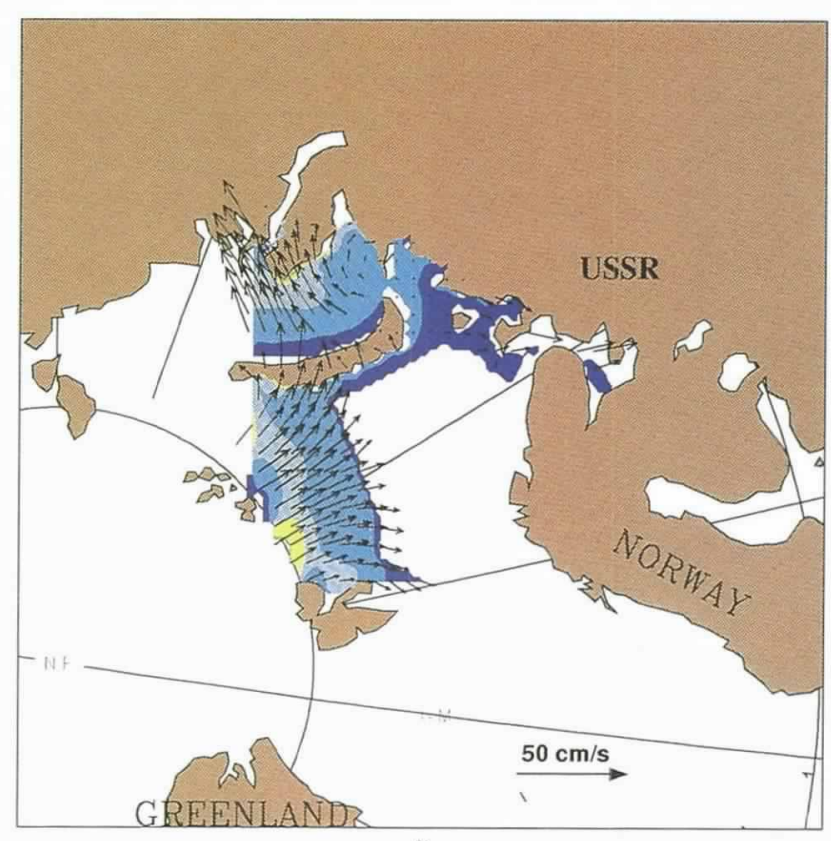

B

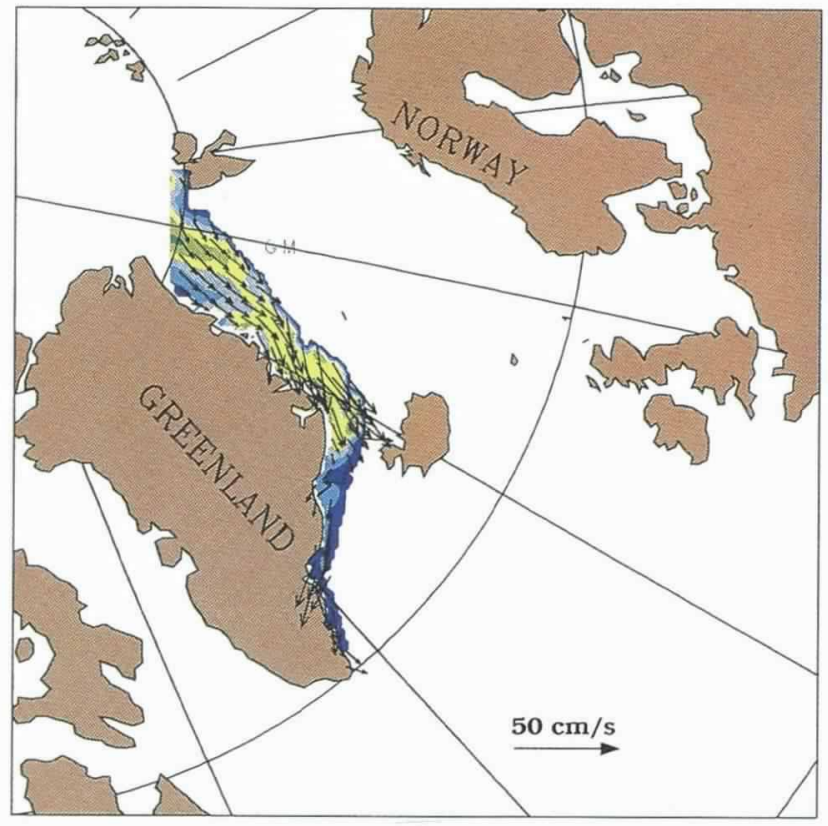

C

Fig. 3: The 24-hour forecast fields of ice thickness and ice drift from May 9, 1991 for (A) PIPS, (B) RPIPS-B, (C) RPIPS-G. Color bar indicates the ice thickness in meters and the scale vector for ice drift is $50 \mathrm{~cm} / \mathrm{sec} . \boldsymbol{B}$ and $\boldsymbol{C}$ use the same color scale. 
Table 1

Daily products available from each of the three Navy sea-ice forecast systems

\begin{tabular}{ll}
\hline \multicolumn{1}{c}{ Field } & \multicolumn{1}{c}{ Forecast Time, hr } \\
\hline Ice Drift & $24,48,72,96,120$ \\
Ice Thickness & 0,120 \\
Ice Concentration & 0,120 \\
Divergence/convergence & $48,96,120$ \\
Ice thickness difference & 120 \\
Ice concentration difference & 120 \\
NOGAPS surface pressure with winds & 0,120 \\
\hline
\end{tabular}

Work is presently underway to examine SSMI data for possible daily model initialization purposes.

\section{Forecast System Products}

A set of 14 products is saved from the 120hour forecast made daily by each forecast system. The fields listed in Table 1 are provided to the JIC to be used as guidance products. Two additional NOGAPS fields, surface pressure with surface winds overlaid, are sent along with the ice products.

Figure 3, A-C, are examples of model-derived 24-hour forecasts of ice thickness and ice drift. This time of year is representative of late-winter conditions in the Arctic. The ice-thickness distribution forecast by PIPS is similar to that seen in under-ice submarine data (Hibler, 1979; Bourke and Garrett, 1987). The average forecast for ice thickness in the central Arctic is from 2.5 to 3.0 $\mathrm{m}$. The thickest ice $(\geq 6.0 \mathrm{~m})$ is found along the Canadian Archipelago, and the thinnest ice is found in the marginal seas. A high pressure system is responsible for the clockwise ice drift, which dominates the Arctic basin. Ice flows southward through the Fram Strait into the Greenland Sea and southward from the central Arctic into the Barents Sea.

The regional forecast systems were developed to provide better resolution of sea-ice conditions near land boundaries and at the ice edge. Similar thickness and drift patterns exist in the regional systems, but with more detail visible in the results, particularly near land boundaries and at the ice edge. RPIPS-B extends into the Kara and White Seas, providing forecasts for these regions not covered by PIPS. Although the general ice-edge pattern forecast by these two systems is similar (e.g., both forecast the southern half of the Barents to be ice free) due to the higher resolution of the ice model, greater detail is found in the RPIPS-B ice edge. A similar situation exists in RPIPS-G, which extends farther south than PIPS, providing ice information south of the Denmark Strait. Similar to the PIPS versus RPIPS-B comparison, the ice edge of RPIPS-G has the same general features as PIPS but with a more highly resolved iceedge location.
Future Plans for Sea Ice Forecasting Systems

The next-generation ice forecasting system, PIPS 2.0, is being designed to include most icecovered regions in the northern hemisphere. Similar to the PIPS and RPIPS systems, the PIPS 2.0 ice model requires atmospheric and oceanic forcing. NOGAPS, a global model, can provide the necessary atmospheric forcing, but the oceanic forcing used by PIPS and RPIPS does not cover the larger area forecast by PIPS 2.0. To obtain the appropriate oceanic forcing, a diagnostic version of a multilevel (15-level), baroclinic, ocean model (Cox, 1984) was coupled to the ice model (Hibler, 1979 and 1980). The ocean model is initialized from a climatology of temperatures and salinity (Levitus, 1982) and uses a Navy data base for bottom topography. Testing of various coupling techniques was first done on the smaller, lesscomputer-intensive region covered by PIPS. Results of this coupling showed that using variable oceanic forcing as opposed to an ocean climatology had a serious impact on the accurate prediction of seasonal and year-to-year variability in the ice cover (Riedlinger and Preller, 1991). In particular, the variability in the oceanic heat flux allowed by this coupling was responsible for a large part of the variability in the ice cover.

Once these models were successfully coupled over the region covered by PIPS, the same techniques were applied to the larger area covered by PIPS 2.0. Part of the coupling included conversion of the ice model from cartesian into spherical coordinates to be compatible with the ocean model. Both the ice and ocean models were first tested separately on the PIPS 2.0 grid, which uses $\frac{1}{2}^{\circ}$ resolution, and then they were coupled. The PIPS 2.0 coupled ice-ocean model is $\sim 30$ times larger $(179 \times 179 \times 15$ grid points versus $47 \times 25 \times 15$ grid points) than the PIPS coupled ice-ocean model and uses a smaller timestep, (30 minutes versus 2 hours) in the ocean model. It is necessary to do the testing of this model on a powerful computer. PIPS 2.0 is presently run on the Navy's Cray YMP computer called the Primary Oceanographic Prediction System (POPS) located at the Stennis Space Center in Mississippi. A similar machine will replace the existing operational computer at FNOC in late 1992.

The PIPS 2.0 coupled ice-ocean model is presently being tested using 1986 NOGAPS forcing. Figure 4 shows the March monthly mean ice thickness and ice drift from a 6-year, near-equilibrium, model integration of PIPS 2.0. Again, the thickest ice is found in the central Arctic along the Canadian Archipelago, and the thinnest ice is in the marginal seas. The ice edge agrees with the JIC's ice-concentration analysis in most places, but in a few locations there is too little ice (e.g., the eastern Bering Sea and Hudson Bay). This may be due to inaccuracies in the predominantly wind-driven ice advection in these locations. Ice
The next-generation

ice forecasting system

... to include most

ice-covered regions in

the northern

hemisphere. 


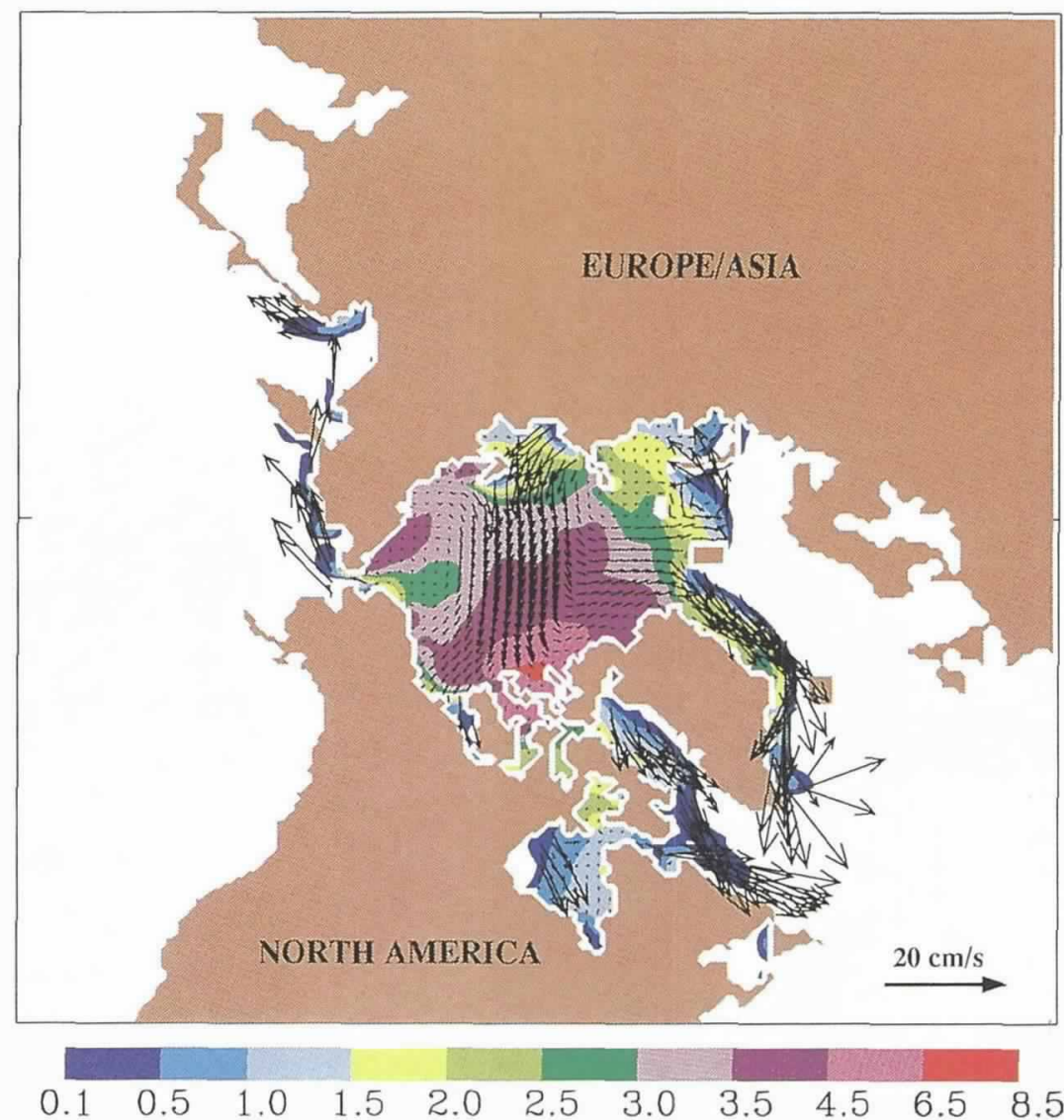

Fig. 4: March 1986 averaged ice thickness and ice drift from the PIPS 2.0 model. Color bar indicates the ice thickness in meters and the scale vector for ice drift is $20 \mathrm{~cm} / \mathrm{sec}$. and the coupling of atmospheric models to the ice-ocean models.

\section{Acknowledgements}

Thanks goes to Ms. Shelley Riedlinger for plotting the figures used in this paper. This project has been funded through the Navy Ocean Modeling and Prediction (NOMP) Program by the Office of Naval Technology (program element $62435 \mathrm{~N}$ ) and by the U.S. Space and Naval Warfare Systems Command (program element $63207 \mathrm{~N}$ ). This paper, NOARL contribution 322 : 068:91, is approved for public release; distribution unlimited.

\section{References}

Bourke, R.H. and R.P. Garrett, 1987: Sea ice thickness distribution in the Arctic Ocean. Cold Reg. Sci. and Technol., 13, 259-280.

Cox, M., 1984: A primitive equation, 3-dimensional model of the ocean. GFDL Ocean Group Technical Report \#I, Geophysical Fluid Dynamics Laboratory, Princeton, NJ, $141 \mathrm{pp}$.

Hibler, W.D. III, 1979: A dynamic thermodynamic sea ice model. J. Phys. Oceanogr., 9, 815-846.

Hibler, W.D III, 1980: Modeling a variable thickness sea ice cover. Mon. Wea. Rev., 108, 1943-1973.

Hibler, W.D. III and K. Bryan, 1987: A diagnostic ice-ocean model. J. Phys. Oceanogr., 17, 987-1015.

Hogan, T.F., T.E. Rosmond and R. Gelaro, 1991: The description of the Navy Operational Global Atmospheric Prediction System's forecast model. Naval Oceanographic and Atmospheric Research Laboratory, Report 13, Stennis Space Center, MS, $221 \mathrm{pp}$.

Levitus, S., 1982: Climatological atlas of the world ocean. NOAA Professional Paper, 13, $173 \mathrm{pp}$.

Parkinson, C.L., J.C. Comiso, H.J. Zwally, D.J. Cavalieri, P. Gloersen and W.J. Campbell, 1987: Arctic sea ice, 19731976: satellite passive-microwave observations. NASA SP-489, Washington, DC, 296 pp.

Parkinson, C.L., 1991: Interannual variability of the spatial distribution of sea ice in the North Polar Region. $J$. Geophys. Res., 96, 4791-4802.

Preller, R.H. and P.G. Posey, 1989: The Polar Ice Prediction System - a sea ice forecasting system. Naval Ocean Research and Development Activity, Report 212, Stennis Space Center, MS, 42 pp.

Preller, R.H., S.H. Reidlinger and P.G. Posey, 1989: The Regional Polar Ice Prediction System-Barents Sea (RPIPS-B): a technical description. Naval Ocean Research and Development Activity, Report 182, Stennis Space Center, MS, 34 pp.

Riedlinger, S.H. and R.H. Preller, 1991: The development of a coupled ice-ocean model for forecasting ice conditions in the Arctic. J. Geophys. Res., 96, 16,955-16,977.

Wohl, G., 1991: Sea ice edge forecast verification program for the Bering Sea. National Weather Digest, 16, 6-12. 